Article

\title{
Japan's dental care under universal health coverage and chal- lenges from population ageing: an analysis on health insurance claims data and dental hygiene survey
}

\author{
Etsuji Okamoto ${ }^{1, *}$ \\ 1 University of Fukuchiyama \\ * Correspondence: okamoto-etsuj@@fukuchiyama.ac.jp
}

\begin{abstract}
Although the universal health coverage (UHC) is pursued by many countries, not all countries with UHC include dental care as their benefits. Japan, with its long-held tradition of UHC, has covered dental care as essential benefit and majority of dental care services are provided to all patients with minimal copayment. Being under the UHC, the scope of services as well as prices are regulated by the uniform fee schedule and dentists submit claims according to the uniform format and fee schedule. The author analyzes the publicly available dental health insurance claims data as well as a sampling survey on dental hygiene and illustrates how Japan's dental care is responding to the challenges from population ageing.
\end{abstract}

Keywords: universal health coverage; health insurance claims; administrative data; claims database

\section{Introduction}

In most countries, dental care is not covered by public insurance or the coverage, if any, may not be universal. On the other hand, dental care is covered by Japan's universal health insurance with some exceptions (e.g., orthodontics). Under Japan's universal health insurance, the prices of each procedure as well as medicines are regulated by government as a form of national uniform fee schedule. Because of such generous coverage, it is technically feasible to grasp utilization of dental care services as national statistics.

Dentists submit itemized claims every calendar month for each patient. The submitted claims data are stored in the national claims database (NDB) and the itemized statistics in a month (typically every May) are published as the "Social Insurance Claims Survey (SICS)". Further, summary statistics of NDB also became availabe as "NDB open data (NDBOD)" after 2014. By combining NDB open data and SICS, one can illustrate the utilization of dental care services.

Also, the dental health status of the entire nation is surveyed through a sampling survey every five to six years, known as "Dental Hygiene Survey (DHS)". The author illustrates the situation of Japan's dental care analyzing claims data and dental hygiene survey.

\section{Materials and Methods}

\subsection{Dental Hygiene Survey}

To survey the dental status of the entire population, the Dental Hygiene Survey (DHS) is conducted as a sampling survey at the interval of five to six years as part of the National Health \& Nutrition Survey. The author analyzed tooth-specific and age-specific survival comparing the latest 2016 results and 2005 results [ $\left.{ }^{1}\right]$.

The sample was selected to reflect the dental health status of the entire population. A total of 150 National Census districts were selected and all residents were subjects of the survey. However, the sex-age distribution of the sample may not properly reflect Japan's population structure as shown in [Table 1,2]. 
[Table 1] The number of subjects of the Dental Hygiene Survey

\begin{tabular}{|c|c|c|c|c|c|c|}
\hline & \multicolumn{3}{|c|}{2005} & \multicolumn{3}{|c|}{2016} \\
\hline & $\mathrm{F}$ & M & MF & $\mathrm{F}$ & M & MF \\
\hline $05 \sim 09$ & 130 & 117 & 247 & 94 & 100 & 194 \\
\hline $10 \sim 14$ & 92 & 116 & 208 & 58 & 64 & 122 \\
\hline $15 \sim 19$ & 65 & 54 & 119 & 32 & 19 & 51 \\
\hline $20 \sim 24$ & 58 & 47 & 105 & 36 & 34 & 70 \\
\hline $25 \sim 29$ & 103 & 71 & 174 & 49 & 37 & 86 \\
\hline $30 \sim 34$ & 142 & 97 & 239 & 95 & 44 & 139 \\
\hline $35 \sim 39$ & 139 & 58 & 197 & 124 & 66 & 190 \\
\hline $40 \sim 44$ & 173 & 74 & 247 & 157 & 97 & 254 \\
\hline $45 \sim 49$ & 164 & 95 & 259 & 125 & 77 & 202 \\
\hline $50 \sim 54$ & 192 & 105 & 297 & 140 & 81 & 221 \\
\hline $55 \sim 59$ & 249 & 158 & 407 & 154 & 100 & 254 \\
\hline $60 \sim 64$ & 242 & 192 & 434 & 213 & 138 & 351 \\
\hline $65 \sim 69$ & 288 & 208 & 496 & 258 & 245 & 503 \\
\hline $70 \sim 74$ & 227 & 221 & 448 & 196 & 184 & 380 \\
\hline $75 \sim 79$ & 183 & 138 & 321 & 164 & 155 & 319 \\
\hline $80 \sim 84$ & 104 & 67 & 171 & 125 & 99 & 224 \\
\hline $85 \sim$ & 46 & 26 & 72 & 72 & 64 & 136 \\
\hline TOTAL & 2597 & 1844 & 4441 & 2092 & 1604 & 3696 \\
\hline
\end{tabular}

[Table2] Age-distribution of the sample of the Dental Hygiene Survey vs. Population

$\underline{\text { Age distribution of the sample of Dental Hygiene Survey vs. Population }}$

\begin{tabular}{l|r|r}
\hline & Dental Hygiene Survey(2016) & Population pyramid(2015) \\
\hline $85 \sim$ & 136 & 3117257 \\
$80 \sim 84$ & 224 & 4961420 \\
$75 \sim 79$ & 319 & 6276856 \\
$70 \sim 74$ & 380 & 7695811 \\
$65 \sim 69$ & 503 & 9643867 \\
$60 \sim 64$ & 351 & 8455010 \\
$55 \sim 59$ & 254 & 7515246 \\
$50 \sim 54$ & 221 & 7930296 \\
$45 \sim 49$ & 202 & 8662804 \\
$40 \sim 44$ & 254 & 9732218 \\
$35 \sim 39$ & 190 & 8316157 \\
$30 \sim 34$ & 139 & 7290878 \\
$25 \sim 29$ & 86 & 6409612 \\
$20 \sim 24$ & 70 & 5968127 \\
$15 \sim 19$ & 51 & 6008388 \\
$10 \sim 14$ & 122 & 5599317 \\
$05 \sim 09$ & 194 & 5299787 \\
\hline
\end{tabular}

\subsection{National Claims Database open data}

National Claims Database (NDB) is arguably one the largest administrative database in the world and started to accumulate the data of medical, dental and pharmaceutical claims since 2009 [ ${ }^{2}$. The dental data became publicly available as "open data" since 2014 and the data are aggregated by clinical diagnoses broken down by sex and fiveyear age groups. The limitation of the data is that it only provides the number of diagnoses and one claim may contain more than one diagnoses. Another limitation of the NDB is legal one: due to the strict privacy protection rule, data smaller than 10 are omitted (one-digit suppression rule). Therefore, one should be cautioned that the data provided by the NDB open data may underestimate the real figures. 


\subsection{Social Insurance Claims Survey (SICS)}

Social Insurance Claims Survey (SICS) is another survey of claims data derived from NDB. The difference from the NDB open data is that 1) SICS contains a monthly data (typically May in the survey year) while the NDB open data provides annual data, 2) One-digit suppression rule does not apply. SICS contains data on the number of claims, the number of office visits and the monetary values for every clinical procedure.

\section{Results}

\subsection{Dental Hygiene Survey}

\subsubsection{Survival of teeth of the elderly}

Survival of teeth of the elderly (65 years or older) has improved even during such a short period of 11 years. As shown in [Figure1], age-specific survival of permanent teeth has improved markedly between the 2005 and 2016 surveys. The improvement is more prominent in the older age groups. Japan Dental Association launched the "80-20 campaign" in 1989, which means "maintaining at least 20 teeth at the age of 80" [ ${ }^{3}$. According to the Dental Hygiene Survey in 1999, 80 year old persons had an average of eight teeth remaining and only $15 \%$ of them had 20 teeth or more remained. According to the Dental Hygiene Survey in 2016, 51.2\% of the elderly aged 80 year old had 20 teeth or more remained.

[Figure 1] Age-specific survival of permanent teeth

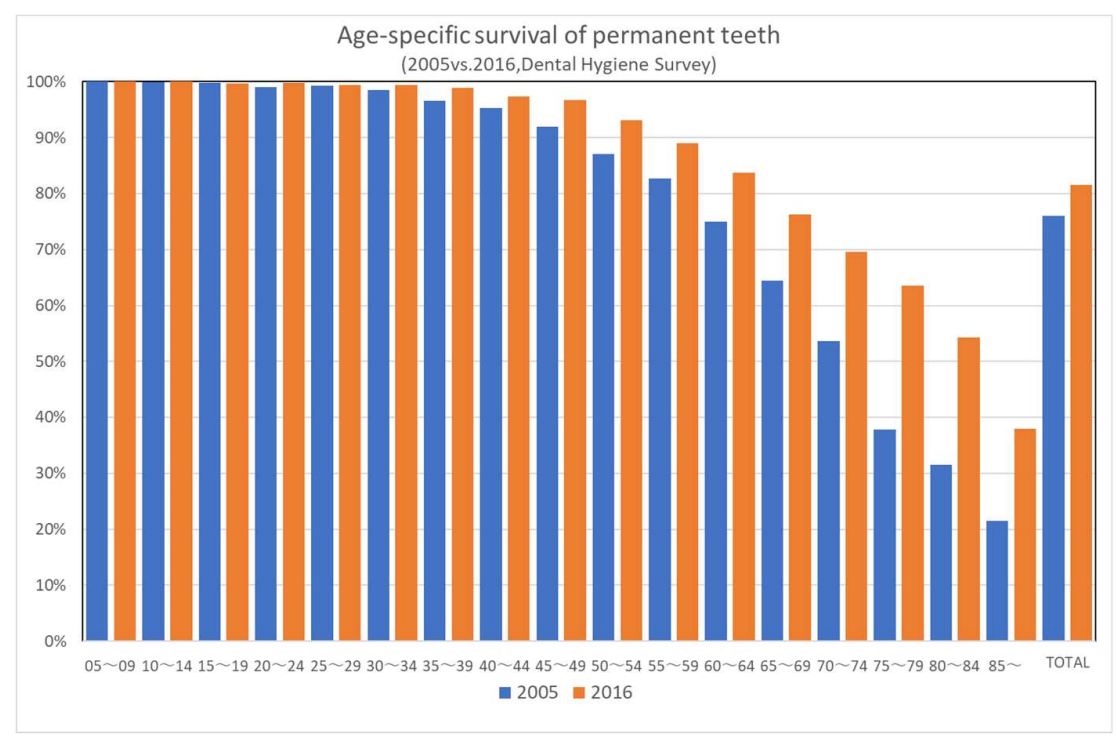

\subsubsection{Tooth-specific survival of the elderly}

The DHS surveys for each tooth. The following table illustrates the tooth-specific improvement in survival for the elderly (>=65 year old). The most improvement in survival was found in the left lower second molar, which showed 1.54 fold improvement in survival (48.4\% survivial in 2016 as opposed to $31.5 \%$ in 2005). On the other hand, the least improvement was right lower canine, which showed 1.16 fold improvement in survival over 11 years interval. Lower canines have the highest survivals in all teeth $(82.5 \%$ for right and $84.1 \%$ for left remaining in the elderly in DHS 2016) and the improvement was inevitably limited.

[Table 3] Tooth-specific survival rate of the elderly and improvement over 11 years (2005-16) 


\begin{tabular}{|c|c|c|c|c|c|c|c|c|}
\hline & \multirow[b]{2}{*}{ median incisor } & \multicolumn{3}{|c|}{$2005(N=1508)$} & \multicolumn{3}{|c|}{$\begin{array}{cr}2016(\mathrm{~N}=1562) & 2 \\
\text { present }[\mathrm{P}] & \text { missing }[\mathrm{M}] \mathrm{P} /(\mathrm{P}+\mathrm{M})\end{array}$} & $2016 / 2005$ \\
\hline & & 890 & 617 & $59.1 \%$ & 1173 & 387 & $75.2 \%$ & 1.27 \\
\hline & lateral incisor & 940 & 563 & $62.5 \%$ & 1215 & 341 & $78.1 \%$ & 1.25 \\
\hline & canine & 1068 & 438 & $70.9 \%$ & 1288 & 274 & $82.5 \%$ & 1.16 \\
\hline \multirow{5}{*}{$\mathrm{R}$} & first premolar & 872 & 636 & $57.8 \%$ & 1148 & 414 & $73.5 \%$ & 1.27 \\
\hline & second premolar & 723 & 785 & $47.9 \%$ & 983 & 576 & $63.1 \%$ & 1.32 \\
\hline & first molar & 508 & 999 & $33.7 \%$ & 781 & 781 & $50.0 \%$ & 1.48 \\
\hline & second molar & 518 & 987 & $34.4 \%$ & 741 & 820 & $47.5 \%$ & 1.38 \\
\hline & \multicolumn{8}{|l|}{ third molar } \\
\hline & median incisor & 895 & 613 & $59.4 \%$ & 1188 & 372 & $76.2 \%$ & 1.28 \\
\hline & lateral incisor & 955 & 551 & $63.4 \%$ & 1225 & 333 & $78.6 \%$ & 1.24 \\
\hline & canine & 1070 & 436 & $71.0 \%$ & 1314 & 248 & $84.1 \%$ & 1.18 \\
\hline \multirow{5}{*}{$\mathrm{L}$} & first premolar & 884 & 624 & $58.6 \%$ & 1182 & 378 & $75.8 \%$ & 1.29 \\
\hline & second premolar & 718 & 789 & $47.6 \%$ & 968 & 594 & $62.0 \%$ & 1.30 \\
\hline & first molar & 494 & 1014 & $32.8 \%$ & 746 & 816 & $47.8 \%$ & 1.46 \\
\hline & second molar & 473 & 1030 & $31.5 \%$ & 755 & 806 & $48.4 \%$ & 1.54 \\
\hline & third molar & 136 & & & 168 & & & \\
\hline \multirow{17}{*}{ upper } & median incisor & 760 & 748 & $50.4 \%$ & 1059 & 502 & $67.8 \%$ & 1.35 \\
\hline & lateral incisor & 773 & 732 & $51.4 \%$ & 1062 & 495 & $68.2 \%$ & 1.33 \\
\hline & canine & 868 & 640 & $57.6 \%$ & 1158 & 402 & $74.2 \%$ & 1.29 \\
\hline & first premolar & 712 & 795 & $47.2 \%$ & 1008 & 550 & $64.7 \%$ & 1.37 \\
\hline & second premolar & 662 & 845 & $43.9 \%$ & 964 & 597 & $61.8 \%$ & 1.41 \\
\hline & first molar & 596 & 912 & $39.5 \%$ & 861 & 701 & $55.1 \%$ & 1.39 \\
\hline & second molar & 561 & 946 & $37.2 \%$ & 817 & 744 & $52.3 \%$ & 1.41 \\
\hline & third molar & 73 & & & 82 & & & \\
\hline & median incisor & 728 & 780 & $48.3 \%$ & 1048 & 514 & $67.1 \%$ & 1.39 \\
\hline & lateral incisor & 733 & 774 & $48.6 \%$ & 1051 & 509 & $67.4 \%$ & 1.39 \\
\hline & canine & 843 & 664 & $55.9 \%$ & 1139 & 422 & $73.0 \%$ & 1.30 \\
\hline & first premolar & 716 & 792 & $47.5 \%$ & 988 & 571 & $63.4 \%$ & 1.33 \\
\hline & second premolar & 667 & 841 & $44.2 \%$ & 919 & 642 & $58.9 \%$ & 1.33 \\
\hline & first molar & 638 & 870 & $42.3 \%$ & 881 & 681 & $56.4 \%$ & 1.33 \\
\hline & second molar & 540 & 968 & $35.8 \%$ & 805 & 754 & $51.6 \%$ & 1.44 \\
\hline & third molar & 67 & & & 75 & & & \\
\hline & & 21229 & 21389 & $49.8 \%$ & 28979 & 15224 & $65.6 \%$ & 1.32 \\
\hline
\end{tabular}

3.1.4. Conditions of teeth of the elderly

Although, the survival of teeth showed a marked improvement over the 11 year interval, the conditions of teeth of the elderly ( $>=65$ year old) did not show much difference over the same period. It is remarkable that the percent of complete dentures among the missing teeth declined from 50.7\% in 2005 to $39.7 \%$ in 2016 . Also remarkable was that the percent of implant increased from $0.3 \%$ of missing teeth in 2005 to $1.3 \%$ in 2016 [Table 4].

[Table 4] Status of teeth of the ederly 


\begin{tabular}{|c|c|c|}
\hline & $2005(\mathrm{~N}=1508)$ & $2016(\mathrm{~N}=1562)$ \\
\hline present teeth & $21229(100 \%)$ & $28979(100 \%)$ \\
\hline sound teeth & $8035(37.8 \%)$ & $11924(41.1 \%)$ \\
\hline with dental sealant & $2(0.0 \%)$ & $5(0.0 \%)$ \\
\hline colored & $366(1.7 \%)$ & $325(1.1 \%)$ \\
\hline not colored & $7667(36.1 \%)$ & $11594(40.0 \%)$ \\
\hline \multicolumn{3}{|l|}{ filled teeth } \\
\hline Crown, not bridge abutment & $2411(11.4 \%)$ & $2677(9.2 \%)$ \\
\hline Crown, bridge abutment & $6143(28.9 \%)$ & $6861(23.7 \%)$ \\
\hline Root cap & & $58(0.2 \%)$ \\
\hline filling & $3165(14.9 \%)$ & $6101(21.1 \%)$ \\
\hline \multicolumn{3}{|l|}{ decayed teeth } \\
\hline Caries incipient & $774(3.6 \%)$ & $750(2.6 \%)$ \\
\hline Caries high grade & $701(3.3 \%)$ & $608(2.1 \%)$ \\
\hline missing teeth & $21389(100 \%)$ & $15253(100 \%)$ \\
\hline implant & $62(0.3 \%)$ & $192(1.3 \%)$ \\
\hline bridges & $1394(6.5 \%)$ & $1585(10.4 \%)$ \\
\hline no prosthesis & $2341(10.9 \%)$ & $2646(17.3 \%)$ \\
\hline complete denture & $10849(50.7 \%)$ & $6060(39.7 \%)$ \\
\hline partial denture & $6743(31.5 \%)$ & $4741(31.1 \%)$ \\
\hline \multirow[t]{2}{*}{ removal for orthodontics } & $0(0.0 \%)$ & $29(0.2 \%)$ \\
\hline & 42618 & 44232 \\
\hline
\end{tabular}

\subsection{National Claims Database}

3.2.1. $\mathrm{N}$ of diagnoses by diagnostic categories

The number of diagnoses contained in dental claims stored in NDB has increased steadily. However, one should be cautioned that the NDB stores only electronically submitted claims and the computerization of claims was not well developed in the early years. Also, the latest 2018 data include approximately 213 million dental claims. There is an increasing trend in the number of diagnoses contained in a claim. The number of diagnoses per claim increased from 1.32 diagnoses per claim in 2014 to 1.63 in 2018 [Table 5].

[Table5]N of dental claims by major diagnostic categories

$\mathrm{N}$ of detanl claims by major diagnostic categories

\begin{tabular}{rrrrrr}
\hline & dental & periodontal & missing & total N of & N of claims $(*)$ \\
& caries & disease & teeth & diagnoses & N of diagnoses/claim \\
\cline { 2 - 5 } 2014 & 107549905 & 140143615 & 16389285 & 264082805 & 200612846 \\
& $40.7 \%$ & $53.1 \%$ & $6.2 \%$ & $100 \%$ & 1.32 \\
2015 & 128939230 & 169719402 & 19330067 & 317988699 & 204865945 \\
& $40.5 \%$ & $53.4 \%$ & $6.1 \%$ & $100 \%$ & 1.55 \\
2016 & 130172602 & 174024015 & 19215128 & 323411745 & 210679509 \\
& $40.2 \%$ & $53.8 \%$ & $5.9 \%$ & $100 \%$ & 1.54 \\
2017 & 132611007 & 184154163 & 19024386 & 335789556 & 212878244 \\
& $39.5 \%$ & $54.8 \%$ & $5.7 \%$ & $100 \%$ & 1.58 \\
2018 & 134161234 & 193685587 & 18840620 & 346687441 & 212916550 \\
& $38.7 \%$ & $55.9 \%$ & $5.4 \%$ & $100 \%$ & 1.63 \\
\hline
\end{tabular}

$* \mathrm{~N}$ of claims: Medical Care Benefit Survey 
The following graph shows a declining share of dental caries with ageing possibly reflecting the declining number of remaining teeth. On the other hand, the share of periodontal diseases remains constant over ageing. However, one should be cautioned in interpreting the NDB data. According to the "one-digit suppression (numbers less than 10 will not be displayed)", the number of claims may be substantially underestimated [Figure 2].

[Figure2] Age-distrubution of the number of diagnoses by major diagnostic categories

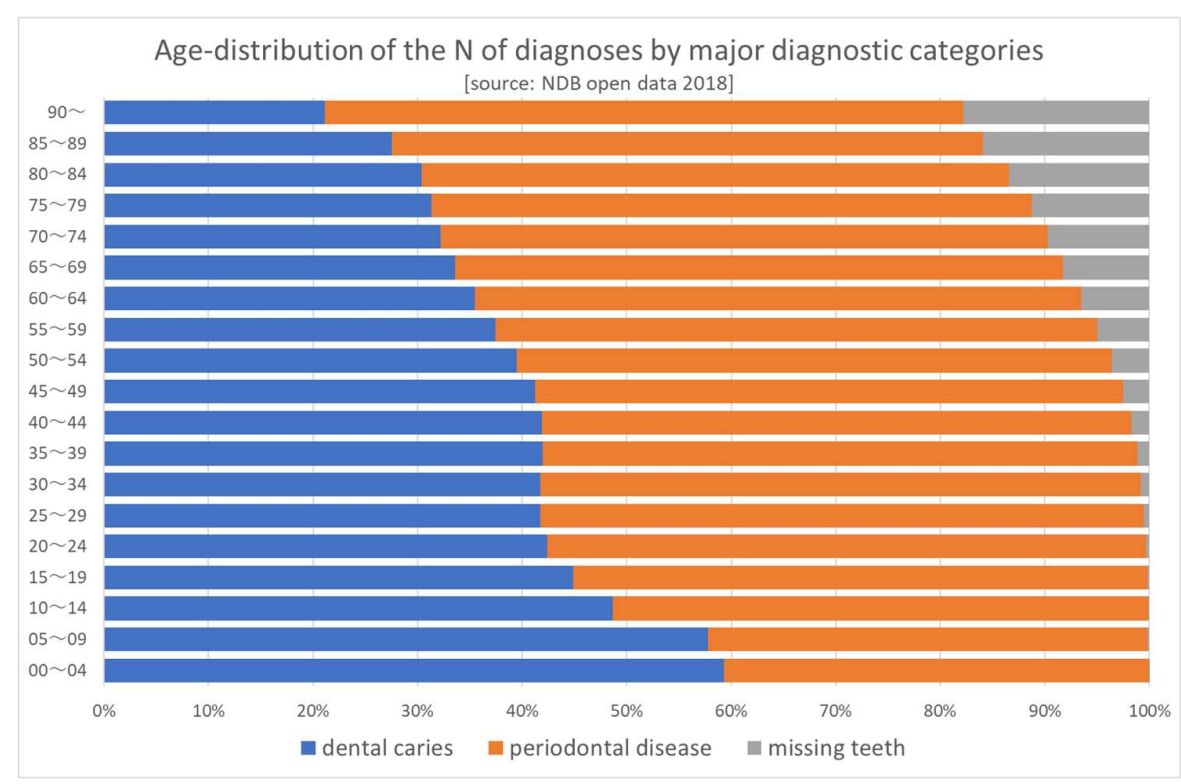

When broken down by ICD10-level diagnoses, two diagnoses (periodontitis and dental caries) account for $57.2 \%$ of the total number and top ten diagnoses account for $82.8 \%$ of the total diagnoses [table 6].

[Table6] Ten most common diagnoses of dental claims

\section{Ten most common diagnoses of dental claims}

\begin{tabular}{lrrr} 
& \multicolumn{1}{c}{$N$ of diagnoses \% diagnose cumulative \% } \\
\cline { 2 - 4 } periodontitis & 135915272 & $39.2 \%$ & $39.2 \%$ \\
dental caries & 62368855 & $18.0 \%$ & $57.2 \%$ \\
gingivitis & 15891362 & $4.6 \%$ & $61.8 \%$ \\
missing teeth & 13615550 & $3.9 \%$ & $65.7 \%$ \\
pulpitis & 13253313 & $3.8 \%$ & $69.5 \%$ \\
chronic periodontitis & 12653681 & $3.6 \%$ & $73.2 \%$ \\
apical perodontitis & 12303356 & $3.5 \%$ & $76.7 \%$ \\
dental caries of 2nd degret & 7958861 & $2.3 \%$ & $79.0 \%$ \\
dental caries treated & 7357028 & $2.1 \%$ & $81.1 \%$ \\
acute purulent periodontiti & 5868951 & $1.7 \%$ & $82.8 \%$ \\
& $\cdot$ & & \\
& $\cdot$ & & \\
TOTAL & $\cdot$ & & \\
\hline
\end{tabular}

source: NDB open data 2018 


\subsection{Social Insurance Claims Survey (SICS)}

The Social Insurance Claims Survey (SICS) has been conducted every year since 1957. It was conducted as a sampling survey when health insurance claims were submitted in paper form. Since 2012, it started to extract data from NDB and became a population survey instead of a sampling survey.

The SICS data covers only one month period (May in the survey year) and is therefore affected by seasonal variation. Also, one should be reminded that the latest data in 2020 is severely affected by the COVID19 epidemic.

The author focuses on home care because it reflects the population ageing. As shown in [Table 7], home care is provided mainly to the elderly population. The age distribution of home care services provision shows a sharp contrast to that of initial office visits.

[Table7] Age distribution of home care/visits and initial office visits

\section{Age distribution of home care/visits and initial office visits (2019)}

\begin{tabular}{|c|c|c|c|}
\hline & $\begin{array}{l}\text { dental home care } \\
\text { management }\end{array}$ & Dental home visits & initial office visits \\
\hline $00 \sim 04$ 歳 & 78 & 435 & 235314 \\
\hline 05～09歳 & 155 & 638 & 518384 \\
\hline $10 \sim 14$ 歳 & 174 & 599 & 313197 \\
\hline 15～19歳 & 301 & 1022 & 149726 \\
\hline 20～24歳 & 786 & 2843 & 193072 \\
\hline 25～29歳 & 1033 & 3564 & 238322 \\
\hline $30 \sim 34$ 歳 & 1420 & 4877 & 280451 \\
\hline 35～39歳 & 1747 & 6174 & 327538 \\
\hline $40 \sim 44$ 歳 & 2753 & 10305 & 388877 \\
\hline 45〜49歳 & 3719 & 14451 & 428651 \\
\hline $50 \sim 54$ 歳 & 3849 & 15898 & 388702 \\
\hline 55～59歳 & 4209 & 19526 & 370018 \\
\hline $60 \sim 64$ 歳 & 5316 & 27306 & 381468 \\
\hline $65 \sim 69$ 歳 & 8450 & 51278 & 465311 \\
\hline 70～74歳 & 13690 & 88495 & 460625 \\
\hline 75～79歳 & 25711 & 176696 & 398915 \\
\hline $80 \sim 84$ 歳 & 43829 & 313163 & 258361 \\
\hline 85〜89歳 & 60312 & 456971 & 131748 \\
\hline 90歳以上 & 74662 & 526285 & 48203 \\
\hline total & 252194 & 1720526 & 5976883 \\
\hline
\end{tabular}

\subsubsection{Dental Home Visits}

Dental home visits are provided to the patients who cannot visit dental clinics for physical handicap and the number of dental home visits is increasing steadily [Table 8]. For the elderly who are living in nursing homes or long-term care facilities, dentists can visit more than one patients at a time. Considering the time saving for such cases, the fee for dental home visits is set considerably lower for multiple patients in a building [11000 yen for one patient and 3610 yen for the second or more patients in a building. The fee is further reduced to 1850 yen for ten or more patients in a building].

[Table 8] The number of dental home visits 
The number of dental home visits

\begin{tabular}{|c|c|c|c|c|}
\hline & $\begin{array}{l}\text { one patient } \\
\text { in a building }\end{array}$ & $\begin{array}{r}2 \sim 9 \\
\text { patients in } \\
\text { a building }\end{array}$ & $\begin{array}{c}10 \text { or more } \\
\text { patients in } \\
\text { a building }\end{array}$ & total \\
\hline 2012 & 205646 & 568505 & & 774151 \\
\hline 2013 & 175332 & 430464 & & 605796 \\
\hline 2014 & 228198 & 277838 & 421356 & 927392 \\
\hline 2015 & 245716 & 356415 & 544678 & 1146809 \\
\hline 2016 & 270419 & 382967 & 597183 & 1250569 \\
\hline 2017 & 305904 & 430549 & 648807 & 1385260 \\
\hline 2018 & 361446 & 628846 & 615724 & 1606016 \\
\hline 2019 & 370991 & 667835 & 642843 & 1681669 \\
\hline 2020 & 295306 & 467573 & 447467 & 1210346 \\
\hline
\end{tabular}

\subsubsection{Dental home care management}

Dental home care management (DHCM) is a surcharge to home visit fees. While home visit fees are reimbursed on every visit, dental home care management is considered to be professional services by dentists involving a planned, scheduled and long-term management of patients to maintain their oral health and nutrition. Therefore, DHCM is reimbursed once a month while home visits may be provided by any dental practitioners, dental home care management expects to be provided by specially designated dental clinics called "home care supporting dental clinics (HCSDC)".

There are certain conditions for dental clinics to be designated a HCSDC. To qualify as HCSDC type1, the clinic must provide 15 times or more home visits per year, and for type 2, 10 times or more.

In addition to the requirement for the number of home visits. The following conditions must be met $\left.{ }^{4}\right]$ :

1) must have at least one dentist who completed a training course on geriatric dentistry as well as risk management for emergencies

2) must have at least one dental hygienist

3) provide patients and/or family members information on home visits in writing

4) must be affiliated with other HCSDCs for back-up

5) must have provided at least five home visits in response to the requests from long-term care facilities (nursing homes, care managers, visiting nursing stations, etc.)

As shown in [Figure3], the number of DHCM has been increasing. Since 2018, the HCSDCs have been divided into two categories: type 1 and 2 . Type 1 HCSDCs are entitled to higher management fee (3200 yen per month per patient) than type 2 (2500 yen) because it must meet the more stringent conditions than type 2 HCSDCs.

[Figure 3] The number of dental home care management fees

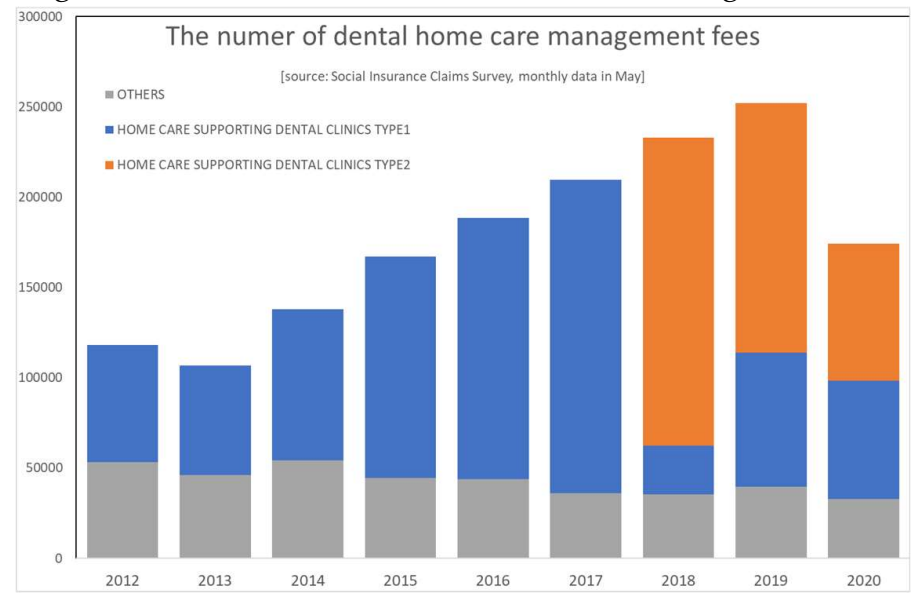




\subsubsection{Home visits by dental hygienists}

A study analyzing the data on dental clinics and patients behavior demonstrated the importance of dental hygienists in influencing the patients' behavior $\left[^{5}\right]$ and tooth $\operatorname{loss}\left[{ }^{6}\right]$. Home visits by dental hygienists are also covered by health insurance. Conditions for reimbursement includes: 1) dental hygienists must spend at least 20 minutes per visit and 2) reimbursement is capped at 4 times per month.

There has been a major revision in the fee schedule for dental hygienists in 2018. Until then, the fee for dental hygienists were two categories: simple (1200 yen) and complicated (3000 yen). However, 2018 and onward, the fee schedule was revised to the same structure of dentists: 3600 yen for the $1^{\text {st }}$ patient in a building, 3280 yen for the $2^{\text {nd }}$ to $9^{\text {th }}$ patient in a building and 3000 yen for the $10^{\text {th }}$ patient or more.

[Table 9] The number of home visits by dental hygienists

$\mathrm{N}$ of home visits by dental hygienists

\begin{tabular}{|c|c|c|c|c|c|c|}
\hline & simple & complicated & $\begin{array}{l}\text { one patient } \\
\text { in a building }\end{array}$ & $\begin{array}{l}\text { 2 9patients } \\
\text { in a building }\end{array}$ & $\begin{array}{l}10 \text { or more } \\
\text { patients in a } \\
\text { building } \\
\end{array}$ & total \\
\hline 2012 & 82621 & 224294 & & & & 306915 \\
\hline 2013 & 77292 & 190608 & & & & 267900 \\
\hline 2014 & 101178 & 225424 & & & & 326602 \\
\hline 2015 & 99210 & 270097 & & & & 369307 \\
\hline 2016 & 107608 & 299310 & & & & 406918 \\
\hline 2017 & 115556 & 333746 & & & & 449302 \\
\hline 2018 & & & 16961 & 54203 & 379964 & 451128 \\
\hline 2019 & & & 17263 & 58139 & 415659 & 491061 \\
\hline 2020 & & & 11165 & 35785 & 282732 & 329682 \\
\hline
\end{tabular}

\subsubsection{Home oral rehabilitation services}

Home oral rehabilitation was added to the health insurance benefit in 2016 as a surcharge to dental home visits. The fee is reimbursed when dentists provide oral rehabilitation services to the patients who are charged "dental home visits". The conditions for reimbursement is 1) patients must have eating disorder requiring a constant dental management, 2) dentists must develop long-term dental management plan and 3) dentists spend at least 20 minutes on site[7].

Since this fee is a surcharge to dental home visits, the fee is categorized by the number of teeth under management, and not by the number of patients in a building.

[Table 10] The number of home oral rehabilitation services

\section{The number of home oral rehabilitation services}

\begin{tabular}{rrrrr}
\hline & $<$ 10teeth & $10 \sim 20$ teeth & $20=<$ teeth & total \\
\cline { 2 - 4 } 2016 & 1931 & 952 & 1441 & 4324 \\
2017 & 2696 & 1608 & 2392 & 6696 \\
2018 & 4798 & 2541 & 3931 & 11270 \\
2019 & 6352 & 3645 & 5686 & 15683 \\
2020 & 4623 & 2891 & 4408 & 11922 \\
\hline
\end{tabular}

\section{Discussion}

Oral health of the elderly population in Japan has improved considerably as evidenced by the Dental Hygiene Surveys. The share of the elderly who maintain 20 or 
more teeth has increased from $15 \%$ in 1999 to $51.2 \%$ in $2016\left[^{8}\right] . \quad$ Tooth-specific survival has improved by $32 \%$ over the eleven years interval.

The improvement is attributable to the increased health insurance coverage to home dental care services, which predominantly are consumed by the elderly patients. Since Japan has universal health coverage and dental care has been included in the benefit, it was possible to illustrate the utilization of dental services as well as the number of diagnoses contained in a claim particularly after the full computerization was achieved and a national database accumulating the claims data was established.

Reflecting the ageing of the entire population, the prevalence of major diagnostic categories has shifted gradually with increasing share of periodontal diseases while the share of missing teeth has decreased due to the improved survival of teeth of the elderly.

Japan's uniform fee schedule is revised every two years and serves as a policy implementation tool for the government. The government has increased the coverage home care services in both medical and dental care. Utilization of home care services has increased steadily in recent years and is expected to increase further reflecting the ageing population (there was a sharp drop in the year 2020. This reflects the impact of the COVID19 epidemic and may be viewed as a temporary phenomenon).

The author analyzed publicly available data source including sampling surveys on dental status as well as health insurance claims data. However, one should be cautioned the limitations and drawbacks of the data. Although Japan's claims data are uniform and comprehensive, it lacks the information on socio-economic status of patients. For example, there are few data available as to the relationship between income and oral health.

Monitoring the socio-economic disparity in oral health status would be the future challenge for researchers.

\title{
5. Conclusions
}

Japan has covered dental care as benefit of its universal health coverage. Thanks to such generous coverage, people can receive dental care with a minimal copayment. The dental health status as measured by survival of teeth has improved considerably particularly for the elderly population. In response to the rapidly ageing population, an increasing trend of home dental care services for the elderly patients has been observed. Although, the overall performance of Japan's dental care for the elderly has been satisfactory, some questions such as socio-economic disparity remains unanswered and leaves room for future research.

Supplementary Materials: Tables and Figures (including figure's data) are available in Excel file [URL]

Funding: This research was funded by the Ministry of Health, Labour \& Welfare as Health, Labour and Welfare Sciences Research Grants "Research on policies for global health issues(21BA1002)".

Institutional Review Board Statement: IRB review was not sought because this study relied solely on publicly available data.

Informed Consent Statement: Same as above.

Data Availability Statement:

\author{
- Dental Hygiene Survey \\ 2005 Survey \\ https://www.e-stat.go.jp/stat-search/file-download?statInfId $=000031411439 \&$ fileKind $=0$ \\ https://www.e-stat.go.jp/stat-search/file-download?statInfId $=000031411440 \&$ fileKind $=0$ \\ 2016 Survey \\ https://www.e-stat.go.jp/stat-search/file-download?statInfId=000031607230\&fileKind $=0$
}




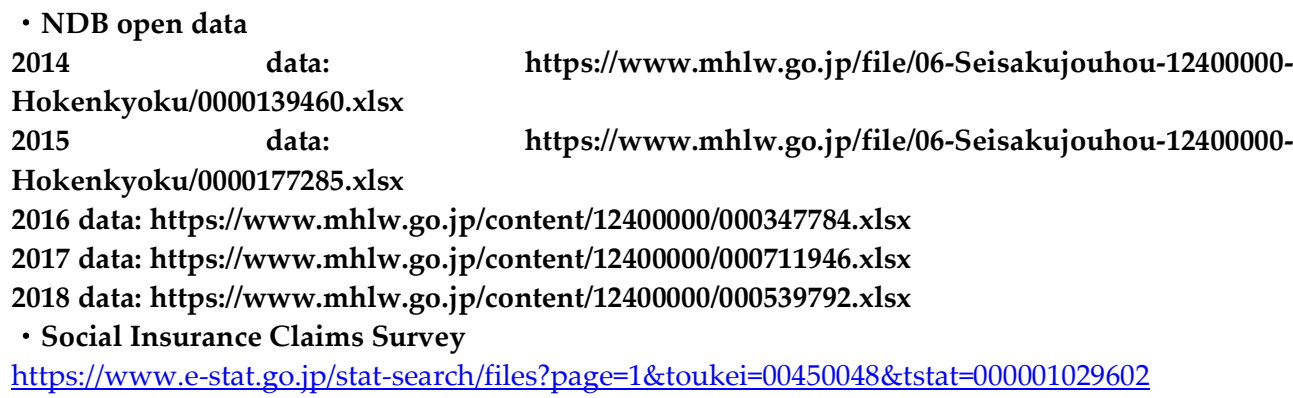

Conflicts of Interest: None to declare.

\section{References}

\footnotetext{
${ }^{1}$ Ando Y, Ikeda N, Nishi N, Tano R, Iwasaki M, Miura H. [Assessment of participation and its associated lifestyle factors in the 2016 National Survey of Dental Diseases: an analysis through record linkage with National Health and Nutrition Survey]. Nihon Koshu Eisei Zasshi. 2021 Jan 30;68(1):33-41.

2 Suzuki S, Noda T, Nishioka Y, Imamura T, Kamijo H, Sugihara N. Evaluation of tooth loss among patients with diabetes mellitus using the National Database of Health Insurance Claims and Specific Health Checkups of Japan. Int Dent J. 2020 Aug;70(4):308-315.

3 Saito M, Shimazaki Y, Fukai K, Furuta M, Aida J, Ando Y, Miyazaki H, Kambara M. A multilevel analysis of the importance of oral health instructions for preventing tooth loss: The 8020 Promotion Foundation Study of Japanese Dental Patients. BMC Oral Health. 2020 Nov 18;20(1):328.

4 Ministry of Health, Labour \& Welfare, Health Insurance Bureau. Directive No.3 on 4th March 2016 [https://www.ssk.or.jp/shinryohoshu/kiso/kiso_s/index.files/kiso_2017_04_03.pdf].

5 Inoue Y, et al. Multilevel Analysis of the Association of Dental-Hygienist-Related Factors on Regular Dental Check-Up Behavior. Int. J. Environ. Res. Public Health 2021, 18(6), 2816

6 Saito, M. et al. A multilevel analysis of the importance of oral health instructions for preventing tooth loss: The 8020 Promotion Foundation Study of Japanese Dental Patients. BMC Oral Health 20, 328 (2020)

7 Ministry of Health, Labour \& Welfare, Health Insurance Bureau. Directive No.3 on 4th March 2016 [https://www.ssk.or.jp/shinryohoshu/kiso/kiso_s/index.files/kiso_2017_04_03.pdf].

${ }^{8}$ Miura H, Tano R. Recent measures in geriatric oral health care in Japan. J of National Institute of Public Health. 68(1):8-16.
} 